\title{
Editorial
}

\section{The Boston Bowel Preparation Scale: Is It Already Being Used?}

\author{
Susana Chaves Marques \\ Department of Gastroenterology, Centro Hospitalar Lisboa Ocidental, Lisbon, Portugal
}

\section{Keywords}

Bowel preparation · Colonoscopy · Endoscopy

\section{A Escala de Preparação Intestinal de Boston: Já Está a Ser Usada?}

\section{Palavras Chave}

Preparação intestinal · Colonoscopia · Endoscopia

Colorectal cancer is one of the most prevalent malignancies worldwide [1]. Routine screening using colonoscopy has contributed to a significant decrease in both colorectal cancer incidence and mortality $[2,3]$. The diagnostic accuracy of colonoscopy requires thorough visualization of the colonic mucosa, and, regardless of technological advances and endoscopists' skills, an adequate bowel preparation is a vital factor to ensure a high-quality procedure. Poor bowel preparation is a major impediment to the effectiveness of colonoscopy as it can lead to missed lesions, incomplete procedures, prolonged cecal intubation and withdrawal times, and repeat procedures at intervals shorter than those recommended [4-7].

Accordingly, several major endoscopic societies, such as the European Society of Gastrointestinal Endoscopy

\section{KARGER}

E-Mail karger@karger.com www.karger.com/pjg
(C) 2018 Sociedade Portuguesa de Gastrenterologia

Published by S. Karger AG, Basel

Karcer

Open access

This article is licensed under the Creative Commons AttributionNonCommercial-NoDerivatives 4.0 International License (CC BYNC-ND) (http://www.karger.com/Services/OpenAccessLicense). Usage and distribution for commercial purposes as well as any distribution of modified material requires written permission.
(ESGE), the American Society of Gastrointestinal Endoscopy (ASGE), and the American College of Gastroenterology (ACG), recommend that every colonoscopy report should include an assessment of the quality of the bowel preparation, ideally after all cleansing maneuvers, like washing and suctioning of the fluid, have been completed [8-12]. Because, until recently, no bowel preparation quality assessment tool had been validated, endoscopists were advised to describe bowel preparation quality using subjective terms, such as "excellent," "good," "fair," and "poor," despite the lack of standardized definitions for these terms. Alternatively, endoscopists could classify bowel preparation quality as "adequate" if it allowed detection of polyps $\geq 5 \mathrm{~mm}$ in size or as "inadequate" if it did not fulfill this requirement [12]. Over the past decade, several scales have emerged in order to better evaluate the adequacy of bowel cleansing for research purposes, such as the Aronchick Scale, the Ottawa Bowel Preparation Scale, the Harefield Cleansing Scale, the Chicago Bowel Preparation Scale, and the Boston Bowel Preparation Scale (BBPS). Attempts to introduce these scales into clinical practice have been limited by the lack of large validation studies $[12,13]$.

The BBPS is a 9-point standardized rating scale developed at Boston University Medical Center (USA) that has been attracting worldwide attention. Unlike previous scales that assess bowel cleanliness encountered during

Dr. Susana Chaves Marques

Department of Gastroenterology, Centro Hospitalar Lisboa Ocidental Rua da Junqueira 126

PT-1349-019 Lisbon (Portugal)

E-Mail xsusanamarx@gmail.com 
initial inspection of the colon, the BBPS assesses bowel preparations during withdrawal of the colonoscope, after all cleansing maneuvers have been adequately performed. Another distinct feature from other scales is that rather than relying on a traditional global assessment of the bowel preparation, the BBPS addresses 3 individual colonic segments: the right colon, the transverse colon, and the left colon. Each segment is given a score from 0 to 3 , and then the 3 individual scores are summed for a total score of 0-9 points [14]. The BBPS has been the most thoroughly validated scale for assessing bowel preparation quality. Since its first publication in 2009, many studies showed that the BBPS is a valid and reliable tool and is associated with clinical outcomes, such as polyp detection rates, colonoscope insertion and withdrawal times, and recommendations for repeat procedures. According to 2 studies published in 2009 and 2010 by the Boston University Medical Center group,

1. the BBPS has a good inter- and intra-observer reliability (weighted $\kappa=0.78,95 \%$ CI $0.73-0.84$, and intraclass correlation 0.91 , respectively) [15];

2. a higher polyp detection rate was documented for BBPS scores $\geq 5$ than scores $<5$ ( 40 vs. $24 \%, p<0.02$ ) [14];

3. total BBPS scores were inversely correlated with both colonoscope insertion and withdrawal times $(r=$ $-0.16, p<0.003 ; r=-0.23, p<0.001$, respectively) [14];

4 . when the BBPS score was $<5$, all physicians recommended repeat colonoscopy within 1 year, and when the BBPS score was $\geq 7$, all physicians recommended repeat colonoscopy according to the regular intervals [15]; and

5. an associated survey revealed that the BBPS is easy to learn and could be readily spread among endoscopists worldwide through a brief web-based instructional video (92\% physicians found the BBPS generally applicable to their patient population, and $67 \%$ adopted it in their routine clinical practice) [15].
In 2010, a larger validation study that included 1,018 screening colonoscopies confirmed some of the results of the former 2 studies: good intra- and inter-observer reliability $(\kappa=0.67,95 \%$ CI $0.95-1.0$, and intraclass correlation 0.99 , respectively) and a higher polyp detection rate for BBPS scores $\geq 5$ than scores $<5$ ( 35 vs. $18 \%, p<0.05$ ) [16].

In this issue of GE - Portuguese Journal of Gastroenterology, Massinha et al. [17] evaluated the reliability of the BBPS in the Portuguese endoscopist community. Their results matched those of previous studies, showing a good inter-observer reliability (intraclass correlation 0.783), independent of endoscopist years of experience and of the number of colonoscopies per month. A very interesting finding of this study was that $75 \%$ of the participants $(n=$ 27) had already been using the BBPS in their clinical practice before this study. However, this study has some limitations, such as the small number of participants $(n=36)$ and the use of static images and video segments of colonoscopies, instead of complete colonoscopy videos. It would be of great value to perform a future study to overcome these limitations and perhaps evaluate the clinical impact of using the BBPS in the Portuguese endoscopist community.

To date, the BBPS is the most reliable and the most clinically relevant bowel preparation scale. It is also easy to learn and simple to use in clinical routine practice. Therefore, the BBPS is the ESGE's preferred bowel quality scale to use according to its recently published guideline "Performance Measures for Lower Gastrointestinal Endoscopy: A European Society of Gastrointestinal Endoscopy (ESGE) Quality Improvement Initiative" [10]. If you are not using it yet, you certainly should (learn how to use it here: http://www.cori.org/bbps/).

\section{Disclosure Statement}

The author has no conflicts of interest to declare.
References
1 Siegel RL, Miller KD, Jemal A: Cancer statistics, 2015. CA Cancer J Clin 2015;65:5-29.

$\checkmark 2$ Centers for Disease Control and Prevention: Vital signs: colorectal cancer screening, incidence, and mortality - United States, 20022010. MMWR Morb Mortal Wkly Rep 2011; 60:884-889.
3 Edwards BK, Ward E, Kohler BA, et al: Annual report to the nation on the status of cancer, 1975-2006, featuring colorectal cancer trends and impact of interventions (risk factors, screening, and treatment) to reduce future rates. Cancer 2010;116:544-573.

4 Burke CA, Church JM: Enhancing the quality of colonoscopy: the importance of bowel purgatives. Gastrointest Endosc 2007;66:565573 
5 Froehlich F, Wietlisbach V, Gonvers JJ, et al: Impact of colonic cleansing on quality and diagnostic yield of colonoscopy: the European Panel of Appropriateness of Gastrointestinal Endoscopy European multicenter study. Gastrointest Endosc 2005;61:378-384.

6 Harewood GC, Sharma VK, de Garmo P: Impact of colonoscopy preparation quality on detection of suspected colonic neoplasia. Gastrointest Endosc 2003;58:76-79.

7 Thomas-Gibson S, Rogers P, Cooper S, et al: Judgement of the quality of bowel preparation at screening flexible sigmoidoscopy is associated with variability in adenoma detection rates. Endoscopy 2006;38:456-460.

8 Rembacken B, Hassan C, Riemann F, et al: Quality in screening colonoscopy: position statement of the European Society of Gastrointestinal Endoscopy (ESGE). Endoscopy 2012;44:957-968.
\9 Hassan C, Bretthauer M, Kaminski MF, et al: Bowel preparation for colonoscopy: European Society of Gastrointestinal Endoscopy (ESGE) Guideline. Endoscopy 2013;45:142155.

10 Kaminski MF, Thomas-Gibson S, Bugajski $\mathrm{M}$, et al: Performance measures for lower gastrointestinal endoscopy: a European Society of Gastrointestinal Endoscopy (ESGE) Quality Improvement Initiative. Endoscopy 2017; 49:378-397.

11 American Society of Gastrointestinal Endoscopy: Quality indicators for colonoscopy. Gastrointest Endosc 2015;81:31-53.

12 Johnson DA, Barkun AN, Cohen LB, et al: Optimizing adequacy of bowel cleansing for colonoscopy: recommendations from the US Multi-Society Task Force on Colorectal Cancer. Gastrointest Endosc 2014;80:543-562.
3 Heron V, Parmar R, Menard C, et al: Validating bowel preparation scales. Endosc Int Open 2017;5:E1179-E1188.

14 Lai EJ, Calderwood AH, Gheorghe D, et al The Boston Bowel Preparation Scale: a valid and reliable instrument for colonoscopy-oriented research. Gastrointest Endosc 2009;69: 620-625.

15 Calderwood AH, Jacobson BC: Comprehensive validation of the Boston Bowel Preparation Scale. Gastrointest Endosc 2010;72:686692.

16 Gao Y, Lin JS, Zhang HD, et al: Pilot validation of the Boston Bowel Preparation Scale in China. Dig Endosc 2013;25:167-173.

17 Massinha P, Almeida N, Cunha I, et al: Clinical practice impact of the Boston Bowel Preparation Scale in a European country. GE Port J Gastroenterol 2018, DOI: 10.1159/ 000485567. 